\title{
Alcohol and Alcoholism in Russia: Insider's Observations and Review of Literature
}

Keywords: Alcohol abuse; Alcoholism; Health care; Russia

\section{Introduction}

The problem of heavy drinking in Russia is well known; but a tendency to exaggerate it in some literature has come to the fore recently. The exaggeration tends to veil shortcomings of the health care, with responsibility for the low life expectancy especially in men (about 20 years difference compared to some more developed countries [1]) shifted onto the patients, that is, supposedly selfinflicted diseases due to the excessive alcohol drinking. During the anti-alcohol campaign (1985-1988), a massive consumption of nonbeverage alcohol was observed: perfumery and technical liquids such as window-cleaner. Considering the large scale of the window cleaner sales in some areas e.g. in Siberia, it was knowingly tolerated by authorities. The alcohol consumption predictably increased after the anti-alcohol campaign. Following the abolition of the state alcohol monopoly in 1992, the country was flooded by alcoholic beverages of poor quality sold through legally operating shops and kiosks. During the 1990s, alcohol was massively transported to Russia from Georgia: the author observed numerous gasoline tankers with ethanol queuing at the border along the Georgian Military Highway. We do not know, from where this alcohol came to Georgia - it was said that it had been imported from other countries. This alcohol was mixed with water and poured out into variably clean vodka bottles, added to fortified wine, beer and other drinks. The Caucasus, Ossetia in particular, has been generally known as a nationwide source of cheap alcoholic beverages. Unpredictability and on average poor quality of sold beverages apparently contributed to a decrease in consumption [2].

\section{Toxicity of Alcoholic Beverages}

It is known in Russia that legally sold alcoholic beverages sometimes caused up to severe and lethal intoxications. The following numbers of lethal poisonings with alcohol-containing liquids were reported: 1998 - 21,800, 1999 - 24,100, 2000 - 27,200 cases [3]. Sales of disinfectant in vodka bottles reportedly resulted in 12,611 cases of hepatotoxicity with jaundice, including 1,189 lethal cases during the period August-November 2006 [4]. Unrecorded figures were higher, as many cases with undiagnosed diseases, unnatural causes of death etc., have been misdiagnosed post mortem as cardiovascular diseases $[5,6]$. About a half of the cases of lethal intoxication with alcohol-containing liquids in some areas were caused by legally sold beverages, while in many lethal cases the alcohol concentration in blood was relatively low [7].

Poor quality alcohol i.e. admixtures are of importance as they may be more toxic than ethanol [8]. With a view to further research, Profs. Ford DA and Korthuis RJ $[9,10]$ kindly agreed to perform toxicological examinations of specimens of vodka and
Journal of

Addiction \& Prevention

\section{Sergei V. Jargin*}

Department of Pathology, People's Friendship University of Russia, Russian Federation, University of Russia, Russia

*Address for Correspondence

Sergei V. Jargin, Department of Pathology, People's Friendship University of Russia, Russian Federation, University of Russia, Clementovski per 6-82, 115184 Moscow, Russia, Tel: +7 495 9516788; E-mail: sjargin@mail.ru

Submission: 08 April, 2016

Accepted: 19 April, 2016

Published: 23 April, 2016

Copyright: ๑ 2016 Jargin SV. This is an open access article distributed under the Creative Commons Attribution License, which permits unrestricted use, distribution, and reproduction in any medium, provided the original work is properly cited.

Reviewed \& Approved by: Dr. Konstantin E. Voronin, Department of Psychiatry and Behavioral Sciences, Medical University of South Carolina, USA

95\% beverage alcohol, acquired in Komi-Permyak Okrug - the part of Russian Federation with one of the lowest life expectancy levels and high alcohol consumption [11]. Preliminary information: gas chromatography with flame ionization detection, using a column separating contaminants, has revealed neither unusual component nor enhanced methanol contents. Hopefully, more information will be obtained by gas chromatography - mass spectrometry, a sensitive method applied to the analysis of alcoholic beverages.

\section{Treatment of Alcoholism}

Treatment of alcoholism in the former Soviet Union (SU) has generally been inefficient, while placebos, persuasion and aversive therapy were the usual methods $[3,12]$. The correctional centers (work-and-treatment prophylactoriums) during the late Soviet time were a form of compulsory treatment with detainment of alcoholics evading therapy, violating public order and work discipline (according to the official formulation), while loopholes were left for the "patients" to obtain alcohol over the fence or alike. Some alcoholics, e.g. after an episode of delirium, were treated in psychiatric hospitals; alcohol was more or less regularly available also there with the help of some attendants. Teturam preparations for implantation, having a placebo effect $[13,14]$, were applied against payment. In the author's opinion, excessive attention was given to "detoxification" which included infusion therapy. Moderate to severe abstinence (withdrawal) symptoms and "post-intoxication state" in alcoholics were defined as indications to intravenous infusion therapy [3]. Note that in conditions of insufficient procedural quality assurance lengthy intravenous therapy can result in complications up to lethal outcomes [15] e.g. viral hepatitis, the more so, as the principle of informed consent has not been sufficiently observed in the former SU [16]. It was also reported about the use of antipsychotics and antidepressants for the treatment of alcohol dependence without evidence-based indications [17].

The "ultra-rapid" (one session) psychotherapy of alcoholism, known in the former SU as coding, should be commented separately. 
This method was started during the anti-alcohol campaign $[18,19]$; it was regarded to be incompatible with medical ethics because of mystification, verbal intimidation, spraying of the throat with ethyl chloride, massage of trigeminal nerve branches, forceful backwards movements of the patient's head etc [20]. The latter may be dangerous for patients with latent vertebral abnormalities. Nonetheless, it continues to be used, being the predominant method of psychotherapy applied by "narcologists" (medical specialists for addictions in the former SU) [21]. This predilection was explained by the economical factor: minimum expenditure and maximum financial gain [22].

\section{Alcohol Policies and their Effects}

The fact that the state, at various times, encouraged alcohol sales is known [23]. Veiled propaganda of alcohol consumption was noticeable between the anti-alcohol campaigns (1972-1985) [24]. Adverse effects of anti-alcohol measures of 1972 and 1958: restrictions of vodka sales with maintenance of queues at retail outlets, their potential contribution to heavy drinking (discussed below) [3,25]. Retrospectively, it has become evident that the antialcohol campaign (1985-1988) was used for political and economical purposes. Its failure and the recoil-effect were predictable and occurred when it was needed: the widespread drunkenness after the campaign facilitated the economical reforms of the early 1990s. Alcohol abusers are prone to emotions of shame, guilt and low selfesteem, being easier to manipulate and to command [26,27]. Workers and some intelligentsia did not oppose privatizations of factories and other state property, occurring not always in agreement with the law, due to their drunkenness, involvement in workplace theft, use of factories' equipment for private purposes etc., which was knowingly tolerated by the management at that and earlier time [28].

There is an impression that efficiency of governmental policies has been exaggerated in $[29,30]$ and some other publications. The effect of recent "specific alcohol control policy measures on alcoholrelated mortality" were discussed in [30] as if alcohol had been a single factor determining changes of mortality. Other factors are not mentioned: availability and adequacy of health care $[6,11]$, low quality and toxicity of some legally sold alcoholic beverages [5,7,31], decline of heavy binge drinking [32], reliability of statistics [6]. At the same time, there is a vacuum in advocacy for the public interest. The following citations are illustrative: "The effect of alcohol taxation measures is likely to be significant and moderately positive. However, its significance was outperformed with much stronger effects of the measures to reduce availability of ethyl alcohol and non-beverage alcohol with very high alcohol content" and "All these measures greatly reduced the amount of ethyl alcohol available..." [30]. In fact, after the end of the anti-alcohol campaign in 1989, vodka and beer have become easily available (no queues as during the Soviet time, more shops and kiosks), while the average salary / minimal vodka price ratio has remained several times higher than prior to the campaign [2,33]. The "crisis of medicine" was discussed in [34], where arguments were presented against the role of this factor in the mortality increase. Validity of these arguments is questionable e.g. the unchanged since the Soviet time mortality rate among stroke patients while the stroke incidence increased. Overdiagnosis of cardio- and cerebro-vascular diseases i.e. unreliability of some statistics has been discussed previously [6]. Decreasing since 1999 infant and maternal mortality, proposed as evidence of health care improvement [34], may reflect priorities in the health care policies but is unrelated to the mortality increase predominantly in men of working age $[35,36]$. Regular medical checkups, performed in many factories and organizations during the Soviet time, albeit sometimes being rather a formality, have been discontinued. There is also mistrust towards medicine because of its commercialization. All medications, some diagnostic and therapeutic procedures are not covered by medical insurance. For these and other reasons, many people stay at home even if they have symptoms, receiving no adequate treatment for chronic diseases. High mortality among ethnic Russian workers and their ongoing replacement by immigrants from regions with lower alcohol consumption, such as Middle Asia and the Caucasus, has apparently contributed to a per capita decrease in alcohol consumption.

Consumption of technical, household liquids and perfumery has decreased abruptly after the anti-alcohol campaign, so that the "nonbeverage alcohol with very high alcohol content" [30] has hardly played any significant role thereafter, apart from medicinal or technical ethanol stolen at some workplaces $[28,36]$. Some alcoholcontaining preparations from the pharmacy, e.g. solution of boric acid or extract of hawthorn, occasionally consumed by alcoholics, include $70 \%$ medicinal alcohol, which must be well purified [37]. Today these preparations are more expensive per unit of alcohol than cheapest vodka. Apparently, there is a tendency to exaggerate consumption of non-beverage alcohol allegedly bought by consumers from the "illegal market" to befog the problem of toxicity of some legally sold beverages [29]. Note that apart from sales of homemade alcohol (samogon) mainly to neighbors in rural areas or reselling at night of beverages legally purchased during the daytime, there is no illegal alcohol retail market in Russia. All vodka and other alcoholic beverages, including imitations of foreign products, those concealed from excise duties or made "in garages" from technical liquids, have been sold through legally operating shops, supermarkets, eateries, and previously also kiosks, generally with the knowledge of authorities $[38,39]$. After the abrogation of the state alcohol monopoly in 1992, the country was flooded by counterfeit and imported alcohol of low quality. Technical, synthetic or cellulosic (manufactured from sawdust by hydrolysis with subsequent fermentation) alcohol with high concentration of substances other than ethanol was massively used for production of vodka and other beverages [2,24,36,40]. The somewhat astringent taste of technical alcohol is known as it was purloined from some factories, railway tank cars, institutes of physics and technology etc $[28,36]$. A tendency of quality improvement of alcoholic beverages has been noticed since approximately the last decade, although some sorts of cheap beer do sometimes reek of technical alcohol. It was stated in [41] that alcohol policies should include measures against production and sales of surrogates. Note that the industry will always manufacture alcohol-containing liquids for technical purposes. Today, given easily available and relatively cheap vodka and strong beer, personnel would hardly ever steal and drink them, as some of them did during the anti-alcohol campaign. What is important is prevention of sales of such liquids in vodka bottles and addition of technical alcohol to beer and wine.

The decrease in mortality since 2006 [30] may have been caused by modernizations in the health care, quality improvement of alcoholic beverages, the tendency of alcohol consumption decrease 
[29], particularly, decline of the heavy binge drinking of vodka [32] partly replaced by moderate consumption of beer [42]. This favorable development should be seen against the background of the spread discipline, intimidation and crime against alcoholics and people with alcohol-related dementia, aimed among others at appropriation of their apartments, houses and other property [43]. Younger people seem to overtake the moderate alcohol consumption style prevailing in many countries. The "specific alcohol control policy measures" introduced in 2006 and thereafter have been rather superficial [30]. These policies may reflect interactions between some groups involved in alcohol production and trade; but they have resulted only in moderate oscillations of vodka price (considering inflation) and no real limitation of its availability. The following prices for a 0.5 vodka bottle were reported before and after the "measures": 2005 - 74.5 rubles; 2007 - 91 rubles [33]. Some policies may even contribute to consumption of higher doses, e.g. disappearance of small (0.33l) beer cans [25]. Another recent measure - the prohibition from 1 January 2013 of beer sales between 23 p.m. and 8 a.m. (the time limit is stricter at some locations) results apparently in purchasing by some people of larger amounts in advance with subsequent consumption. The prohibition of beer sales from kiosks may have a similar effect in places with no shops nearby. There is an opinion that the latter measure has no impact on the volume of beer sales [44]. Summarizing this paragraph, physical restrictions of alcohol availability may lead to a decrease in the total alcohol consumption; but they might contribute to heavier occasional intoxications i.e. binge drinking [45]. In this way acted queues at retail outlets maintained during the Soviet time after the restrictions of vodka sales introduced in 1958 [3]. After queuing, larger amounts of alcohol were usually purchased and consumed. Analogously, having waited in a queue at the entrance of a beer house (pivnoi bar), companies or couples usually stayed there for hours.

As discussed above, vodka and beer have remained considerably more affordable and physically available for a majority of the population than it was prior to the anti-alcohol campaign $[2,33]$. Admittedly, there are people with low incomes, for whom the prices are high, which is caused by insufficient social support and low unemployment benefits. Poor public assistance is also one of the causes of persistence of illegal businesses including those with alcohol: an alternative for some business people would be extreme poverty. In fact, the anti-alcohol rhetoric is distracting public attention from shortages of health care and public assistance.

\section{Alcohol and Public Health}

Considering the above and previously published arguments, certain policies contributed to higher mortality among workers, paupers, and other social groups $[2,25,46]$. Apart from alcohol, limited availability of high-quality health care is a cause of the relatively low life expectancy in Russia especially among men, who are under represented among visitors of governmental policlinics. The medication costs for an outpatient treatment are not covered by the medical insurance. Adequate therapy is hardly available for many people. Irregular treatment of hypertension has been a major problem in the former SU, contributing to the cardio- and cerebrovascular mortality [47]. At the same time, it is well known that diagnoses of cardiovascular diseases have often been written on death certificates in unclear cases [5,6], in particular, during the 1990s along with the deterioration of the autopsy service and the health care in general [48]. Overestimation of the cardiovascular mortality and of its cause-effect relationship with the alcohol consumption e.g. in [49-51] has shifted responsibility for high mortality from health care authorities to patients, allegedly suffering of self-inflicted diseases due to excessive alcohol consumption.

The per capita alcohol consumption has been decreasing since approximately the last decade [52]. The heavy binge drinking was reported to decline in Moscow and St. Petersburg, which agrees with our observations [32]. A similar tendency has also been noticed in some rural areas and small towns, favored by the immigration from the regions with less widespread alcohol consumption, or explained by the fact that local alcoholics have "died out" with fewer successors. During the Soviet time and shortly afterwards, many heavily drunk individuals could be observed in public places. There are not so many inebriated people in the streets today. On the contrary to the past, even marginalized people are rarely seen drunk in public. Looking at them, recognizable features of chronic alcohol consumption can be seen infrequently (Figure 1). The incidence of alcoholism and of alcohol psychoses was reported to be decreasing since approximately $2003[3,53]$.

In this connection, the previously discussed [54,55] study of the Techa River Cohort (population of the area with a longstanding radioactive contamination) [56-58] gives an illuminating example. By the low individual doses, the cause-effect relationship between radiation and cardiovascular disease is a priori improbable [54,55]. The excess relative risk (ERR) of death from a cardiovascular disease per dose unit of radiation was significantly influenced by the gender, ethnicity and place of residence (Table 1). It can be reasonably assumed that quality of health care in Chelyabinsk oblast (province) is higher than in Kurgan province because the million city of Chelyabinsk is a center with modern medical institutions. Considering the tendency of post mortem overdiagnosis of cardiovascular diseases in unclear cases, the registered cardiovascular mortality must inversely correlate with diagnostic quality [6]. This tendency is known; official statistics may be trimmed to mask interregional differences in health care

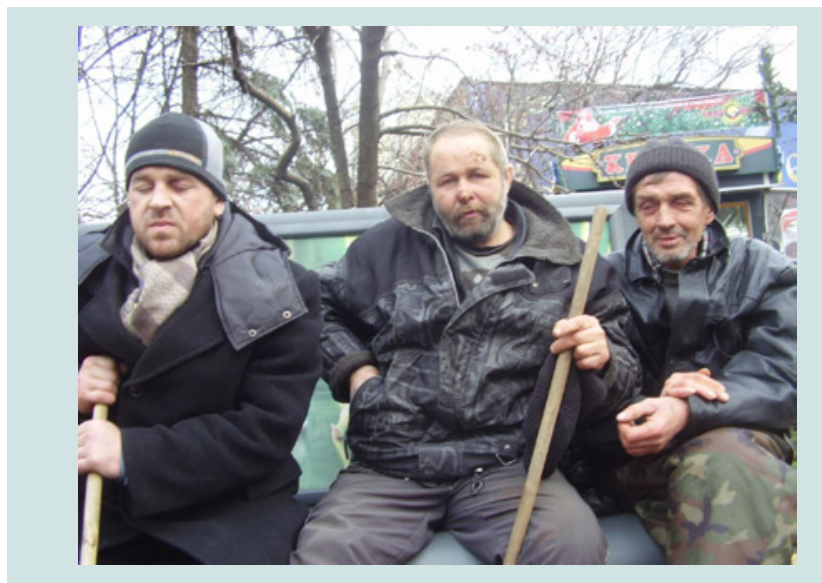

Figure 1: Marginalized-looking people in Moscow. No external signs of regular alcohol consumption are recognizable. Consent to photographing was obtained against payment. 
Table 1: An extract from the Table 7 from [56] "Dose response and effect modification parameter estimates for mortality from diseases of the circulatory system (DCS)".

\begin{tabular}{|l|c|c|c|}
\hline \multicolumn{1}{|c|}{} & \multicolumn{2}{|c|}{ \% ERR per $\mathbf{0 . 1}$ Gy } & Ratio \\
\hline Gender & Men - 7.8 & Women - 1.3 & Male/Female = 6 \\
\hline $\begin{array}{l}\text { O b I a s t } \\
\text { (province) }\end{array}$ & Kurgan - 72.0 & $\begin{array}{c}\text { Chelyabinsk } \\
-3.7\end{array}$ & $\begin{array}{c}\text { Kurgan/Chelyabinsk = } \\
19.5\end{array}$ \\
\hline Ethnicity & $\begin{array}{c}\text { Turkic (Tatar and } \\
\text { Bashkir) - 14.2 }\end{array}$ & Slavic - 2.4 & Turkic/Slavic = 6 \\
\hline
\end{tabular}

ERR: Excess Relative Risk; Gy (Gray): Dose Unit of lonizing Radiation

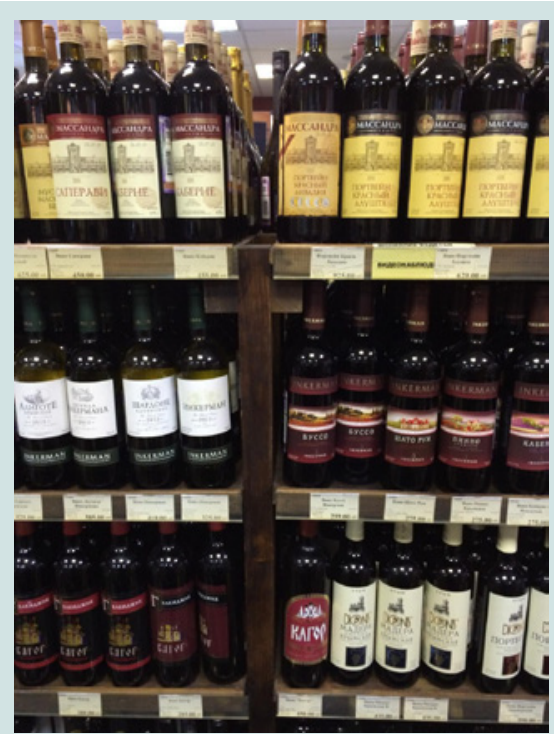

Figure 2: Shelves of a bottle store not far from the center of Moscow. Port (Portwein), Madera and Kagor (Cahors) are visible.

quality. ERR of cardiovascular diseases in an independent study can be seen, other things being equal, as a surrogate indicator of the health care quality [56]. The gender differences are understandable: it is known that middle-aged and elderly men generally visit health care centers (policlinics) less often than women of the same age. A tentative counting in a Moscow policlinic produced male/female ratios from $1 / 3$ to $1 / 20$ in the age category older than 50 years. Alcohol abusers, who are predominantly males, are sometimes unwelcome in medical institutions; they were not always treated in accordance with medical ethics [59]. War veterans enjoy advantages in the health care; there are, however, misgivings that the veteran status has been awarded gratuitously to some individuals from the privileged milieu [60]. The effect of ethnicity as a factor was probably analogous to that of gender. On the contrary to cardiovascular diseases, the registered cancer mortality must positively correlate with the quality of diagnostics, autopsy rates etc. It is not surprising that the cancer death rate among residents of Chelyabinsk province was found to be significantly ( $\mathrm{P}$ $<0.001$ ) higher than in Kurgan province, while all factors presented in the Table 1 had the opposite effect on the solid cancer mortality compared to cardiovascular diseases [56,58].

\section{Alcoholic Beverages and their Quality}

It is often assumed [e.g. [61]] that vodka has been the predominant form of consumed alcohol in the former SU. In fact, fortified wines with alcohol concentration around 17-19\% by volume were massively produced and sold till 1986. It is evident for an inside observer that, especially during the period between the two anti-alcohol campaigns (1972-1985), the part taken by fortified wines was considerable, being larger than that of vodka at least in some parts of the country. The ratio was more or less preserved during the anti-alcohol campaign (1985-1988), when vodka price doubled, but relatively cheap wines were still available, acknowledging that their quality declined and there were long queues at retail outlets. Some fortified wines were obviously more toxic than vodka per unit of alcohol; their consumption resulted in deeper intoxications and hangovers, e.g. potency derangements after their use were reported in 1988-1989 and later. However, somewhat more expensive fortified wines were acceptable quality: they were made from grapes or fruit by fermentation with addition of distilled alcohol from grain or other fermented plant material. Manufacturing according to the standards turned out to be expensive in conditions of the market economy, the more so as cheap technical alcohol, not used up by factories being closed at that time, has been at disposal. Many well-known wines and spirits disappeared around 1990; some of their names have continued to be used for selling of products containing non-purified synthetic or cellulosic alcohol, artificial aromas and dyestuff [36,62].

During the Soviet time, imitations of many internationally known wines and spirits were produced. Imitations of Port, Madeira (Madera), Vermouth and other fortified wines were popular because of the higher alcohol concentration and relatively low price; but the quality, apart from the cheapest varieties, was often acceptable or good. Matters changed in 1985 with the start of the anti-alcohol campaign, when the quality of alcoholic beverages deteriorated. After the campaign, together with transition to the market economy, new labels appeared and disappeared, while beverage qualities and labels correlated poorly. New products were sometimes good in the beginning but later got worse. Well-known Soviet-time wines and cognacs disappeared, changed their taste or were replaced by surrogates. Even today, beverages with the same label can taste differently. The share taken by falsified products has been variable, being apparently lower in Moscow than in smaller towns. The quality of counterfeit vodka has depended on the origin: it could be a standard product concealed from excise duties or a solution of technical alcohol with a high concentration of substances other than ethanol [36].

Imported wine of high quality is expensive, while cheap natural wines have largely disappeared. Some are made of concentrate possibly with addition of some natural wine. There are more expensive Port, Madeira and Sherry imitations, produced in the south of Russia and Ukraine, resembling foreign originals but sometimes smelling technical alcohol. After 1990, imitation and falsification of foreign beverages has become widespread $[38,62]$. A consumer often does not know, whether he is drinking a counterfeit imitation, or an imported wine adapted for the Russian market. Research on improvement of Port, Sherry (Jerez), Madeira, Cognac, whiskey and Calvados is continued [63-68]. In some publications, Cognac imitations are named brandy [69] and those of Port - "wine of Portwein type" [70]. 
Nonetheless, both products are sold now as before labeled as Cognac or Portwein (Figure 2). The same product can be named brandy if exported, while in Russia it is sold with the label "Cognac" [69]; the same pertains to Sekt vs. Champagne. The brand "Russian Cognac" is currently promoted [71]. As far as we know, in the West are sold only original products of the above-named denominations, in accordance with the protected geographical status framework. The problem waits for its solution: under which names and labels the imitations can be legitimately produced and sold. The optimal way, in our opinion, would be preservation of certain traditionally used names such as "Crimean Madera" since consumers are accustomed to them. Champagne-type wines could be named Sekt, Brut, or sparkling wine; and Port-type wines - Ruby or Tawny or be numbered (e.g. Portwein no. 33 or 72 ) as they were in the former SU, and these denominations can be used under the condition of adherence to the original formula.

\section{Conclusion}

Russia has made a step from her alcoholic past. However, there is still a need to prevent the right violations of people suffering from alcoholism and alcohol-related dementia, aimed at appropriation of their residences and other properly, as well as suboptimal treatment of such people in governmental medical institutions. Apart from excessive alcohol consumption, the following causes of the relatively low life expectancy in Russia, not clearly perceptible from professional literature, should be pointed out: insufficient quality and availability of health care especially for middle-aged and elderly men, including those prone to the alcohol consumption; low quality and toxicity of some legally sold alcoholic beverages, acknowledging that there have been improvements during the last decade. If civilization is our future we can follow the example of more developed countries, where aged alcohol-dependent citizens can spend time in beer or wine houses and then go home under the condition of maintenance of the public order.

\section{References}

1. Zatonski WA, Bhala N (2012) Changing trends of diseases in Eastern Europe: closing the gap. Public Health 126: 248-252.

2. Jargin SV (2010) Letter from Russia: minimal price for vodka established in Russia from 1 January 2010. Alcohol Alcohol 45: 586-588.

3. Ivanets NN, Vinnikova MA (2011) Alcoholism. MIA: Moscow.

4. Ostapenko luN, Sentsov VG (2014) Current incidence and mortality of acute intoxications by chemicals in Russian Federation. In: Luzhnikov EA (Eds) Medical Toxicology. National Manual. Geotar-Media: Moscow, Russia, pp. 23-36

5. Davydov MI, Zaridze DG, Lazarev AF, Maksimovich DM, Igitov VI, et al. (2007) Analysis of mortality in Russian population. Vestn Ross Akad Med Nauk 7: 17-27.

6. Jargin SV (2015) Cardiovascular mortality trends in Russia: possible mechanisms. Nat Rev Cardiol 12: 740

7. Nuzhnyi VP, Kharchenko VI, Akopian AS (1998) Alcohol abuse in Russia is an essential risk factor of cardiovascular diseases development and high population mortality (review). Ter Arkh 70: 57-64

8. Rohsenow DJ, Howland J (2010) The role of beverage congeners in hangover and other residual effects of alcohol intoxication: a review. Curr Drug Abuse Rev 3: 76-79.

9. Korthuis RJ (2004) Introduction to the special topics issue on alcohol and cardioprotection. Pathophysiology 10: 81-82.
10. Ford DA (2010) Lipid oxidation by hypochlorous acid: chlorinated lipids in atherosclerosis and myocardial ischemia. Clin Lipidol 5: 835-852.

11. Goss PE, Strasser-Weippl K, Lee-Bychkovsky BL, Fan L, Li J, et al. (2014) Challenges to effective cancer control in China, India, and Russia. Lancet Oncol 15: 489-538.

12. Fleming PM, Meyroyan A, Klimova I (1994) Alcohol treatment services in Russia: a worsening crisis. Alcohol Alcohol 29: 357-362.

13. Johnsen J, Mørland J (1992) Depot preparations of disulfiram: experimental and clinical results. Acta Psychiatr Scand Suppl 369: 27-30.

14. Wilson A, Blanchard R, Davidson W, McRae L, Maini K (1984) Disulfiram implantation: a dose response trial. J Clin Psychiatry 45: 242-247.

15. Serov VV, Popov MS, Zairat'iants OV (1988) Pathologicoanatomic evaluation of the sequelae of medical manipulations. Arkh Patol 50: 11-16.

16. Jargin SV (2014) Invasive procedures with questionable indications. Ann Med Surg (Lond) 3: 126-129.

17. Mendelevich VD, Zalmunin KY (2015) Paradoxes of evidence in Russian addiction medicine. Int J Risk Saf Med 27 Suppl 1: S102-S103.

18. Dovzhenko AR, Artemchuk AF, Bolotova ZN, Vorob'eva TM, Manuilenko IuA (1988) Outpatient stress psychotherapy of patients with alcoholism. Zh Nevropatol Psikhiatr Im S S Korsakova 88: 94-97.

19. Lipgart NK, Goloburda AV, Ivanov VV (1991) Once more about A.R Dobzhenko's method of stress psychotherapy in alcoholism. Zh Nevropatol Psikhiatr Im S S Korsakova 91: 133-134.

20. Voskresenskii VA (1990) Critical evaluation of ultra-rapid psychotherapy of alcoholism (concerning the article by A.R. Dovzhenko et al. "Ambulatory stress psychotherapy of alcoholics"). Zh Nevropatol Psikhiatr Im S SKorsakova 90: 130-132.

21. Torban M, Heimer R, llyuk RD, Krupitsky EM (2011) Practices and attitudes of addiction treatment providers in the Russian Federation. J Addict Res Ther 2: 104

22. Khudiakov AV (2006) Psychotherapy and narcology: love without requital. Narkologiia 11: 67-68.

23. McKee M (1999) Alcohol in Russia. Alcohol Alcohol 34: 824-829.

24. Jargin SV (2010) On the causes of alcoholism in the former Soviet Union. Alcohol Alcohol 45: 104-105.

25. Jargin SV (2015) Alcohol abuse in Russia: history and perspectives. J Addict Behav Ther Rehabil 4:1.

26. Scherer M, Worthington EL, Hook JN, Campana KL (2011) Forgiveness and the bottle: promoting self-forgiveness in individuals who abuse alcohol. J Addict Dis 30: $382-395$

27. Potter-Efron RT, Carruth B (2002) Shame, guilt, and alcoholism: treatment issues in clinical practice. Routledge, Haworth Press, New York.

28. Treml VG (1990) Study of employee theft of materials from places of employment. Berkeley-Duke occasional papers on the second economy in the USSR 20.

29. Radaev V (2015) Impact of a new alcohol policy on homemade alcoho consumption and sales in Russia. Alcohol Alcohol 50: 365-372.

30. Khaltourina D, Korotayev A. (2015) Effects of specific alcohol control policy measures on alcohol-related mortality in Russia from 1998 to 2013. Alcohol Alcohol 50: 588-601.

31. Razvodovsky YE (2013) Affordability of alcohol and alcohol-related mortality in Belarus. Adicciones 25: 156-162.

32. Perlman FJ (2010) Drinking in transition: trends in alcohol consumption in Russia 1994-2004. BMC Public Health 10: 691

33. Prices on vodka in the last hundred years.

34. Khaltourina DA, Korotayev AV (2013) Russian cross. Factors, mechanisms and ways out of the demographic crisis in Russia. 
35. Shield KD, Rehm J (2015) Russia-specific relative risks and their effects on the estimated alcohol-attributable burden of disease. BMC Public Health 15: 482.

36. Nemtsov AV (2009) Alcoholic history of Russia: contemporary period. Moscow.

37. Khaltourina DA (2008) Comment on the article by D.A. Leon and co-authors "Hazardous alcohol drinking and premature mortality in Russia: a population based case-control study". Narkologiia 8: 79-80.

38. Jargin SV (2013) Changing pattern of alcohol consumption in Russia Adicciones 25: 356-357.

39. Urumbaeva RN (2009) On influence of different factors on the scale of illegal market of alcohol in Russian Federation. Manufacture of Alcohol and Liqueur \& Vodka Products (Moscow) 3: 4-5.

40. Nuzhnyi VP (1995) Toxicological characteristic of ethyl alcohol, alcoholic beverages and of admixtures to them. Voprosy Narkologiia 3: 65-74.

41. Khaltourina DA (2007) Alcohol policy: global experience and Russian realities. Narkologiia 5: 10-18.

42. WHO (2014) Global Status Report On Alcohol and Health. Geneva.

43. Jargin SV (2015) Elder abuse, manipulation towards suicide, and homicide: borders can be vague. Int J Emerg Ment Health.

44. MacFarlane S (2012) Regulation of brewing in Russia - one of the toughest. Beer and Beverages (Moscow) 1: 48-49

45. Babor T, Caetano R, Casswell S, Edwards G, Giesbrecht N, et al. (2004) Alcohol: no ordinary commodity. Research and public policy ( $\left.2^{\text {nd }} \mathrm{Edn}\right)$, Oxford University Press, Oxford.

46. Jargin SV (2016) Alcoholic beverage type and pancreatitis: a letter from Russia. Pancreas 45: e18-e19.

47. Roberts B, Stickley A, Balabanova D, Haerpfer C, McKee M (2012) The persistence of irregular treatment of hypertension in the former Soviet Union. J Epidemiol Community Health 66: 1079-1082.

48. Jargin SV (2010) The practice of pathology in Russia: on the eve of modernization. Basic Appl Pathol 3: 70-73.

49. Vertkin AL, Zairat'iants OV, Vovk EI (2009) Final diagnosis. Geotar-Media Moscow, Russia.

50. Nemtsov AV (2002) Alcohol-related human losses in Russia in the 1980s and 1990s. Addiction 97: 1413-1425.

51. Paukov VS, Erokhin luA (2004) Pathologic anatomy of hard drinking and alcoholism. Arkh Patol 66: 3-9.

52. Neufeld M, Rehm J (2013) Alcohol consumption and mortality in Russia since 2000: are there any changes following the alcohol policy changes starting in 2006? Alcohol Alcohol 48: 222-230.

53. Koshkina EA, Kirzhanova VV, Babicheva LP, Mugantseva LA (2013) The activity of drug addiction service of the Russian Federation: an assessment of statistical parameters and an analysis of results. Zh Nevrol Psikhiatr Im S S Korsakova 113(6 Pt 2): 3-8.

54. Jargin SV (2013) On the low-dose-radiation exposure in the Techa River
Cohort and mortality from circulatory diseases. Radiat Environ Biophys 52: 419-420.

55. Jargin SV (2016) Biological effectiveness of ionizing radiation: acute vs. protracted exposures. J Environ Stud 2: 5.

56. Krestinina LY, Epifanova S, Silkin S, Mikryukova L, Degteva M, et al. (2013) Chronic low-dose exposure in the Techa River Cohort: risk of mortality from circulatory diseases. Radiat Environ Biophys 52: 47-57.

57. Krestinina LY, Akleyev AV (2013) Reply to "On the low-dose radiation exposure in the Techa River Cohort and mortality from circulatory diseases" by Jargin (2013). Radiat Environ Biophys 52: 421-423.

58. Schonfeld SJ, Krestinina LY, Epifanova S, Degteva MO, Akleyev AV, et al. (2013) Solid cancer mortality in the Techa River Cohort (1950-2007). Radiat Res 179: 183-189.

59. Jargin SV (2015) Some aspects of renal biopsy for research. Int J Nephrol Kidney Failure 1.

60. Jargin SV (2015) Some selected solutions for Ukraine. J Def Manag 5: 130.

61. Razvodovsky YE (2015) The effect of beverage type on alcoholic psychoses rate in Russia. Alcohol Alcohol 50: 200-205.

62. Zaichik CR, Tiagilev AO (2007) Wine label. Moscow.

63. Adzhiev AM, Gadzhiev GR, Grigoriants BV (2005) Some scientific and practical aspects of the cognac production development in Dagestan, In: Innovations and efficiency of manufacturing processes in viticulture and winemaking. Russian Academy of Agricultural Sciences: Krasnodar 2: 188190.

64. Alekseeva RV (2009) Development of manufacturing technology of the special wine Portwein from perspective sorts of grapes. Dissertation, Kuban Technological University, Krasnodar, Russia.

65. Blagoz AR, Ageeva NM (2007) Manufacturing of Calvados in the Republic of Adygea. Winemaking and Viticulture (Moscow) 5: 16-17.

66. Kushkhova RB (2014) Technology development of strong vintage (marochnoe) wines of Madera-type. Dissertation, Magarach National Institute for Vine and Wine, Yalta.

67. Lubchenkov PP, Lubchenkova NA, Lubchenkov AA, Parkhunov BG Parkhunov VB, et al. (2005) Special features of manufacturing of "Praskoveiskoe" whiskey. In: Innovations and efficiency of manufacturing processes in viticulture and winemaking. Russian Academy of Agricultural Sciences: Krasnodar 2: 180-188.

68. Cherviak SN (2014) Technology development of Sherry (Jerez) wines and wine materials for production of dry table Sherry. Dissertation, Magarach National Institute for Vine and Wine, Yalta.

69. Khiabakhov TS (2005) Main improvement directions of manufacturing technology of Russian brandy. In: Innovations and efficiency of manufacturing processes in viticulture and winemaking. Russian Academy of Agricultural Sciences: Krasnodar 2: 191-196.

70. Agafonova NM (2014) Technology development of Portwein-type wines with low sugar contents. Dissertation, Magarach National Institute for Vine and Wine, Yalta.

71. Information (2015) The largest manufacturers established Cognac Union Winemaking and Viticulture (Moscow) 5: 58.

\section{Acknowledgements}

The author is sincerely grateful to Professor Konstantin E. Voronin. 